\title{
Development and Evaluation of Nanoscale Sorbents for Mercury Capture from Warm Fuel Gas
}

\section{Evaluation of Binary Metal Oxides for Mercury Capture (Task 5) \\ Topical Report -5}

Reporting Period

October 01, 2005 - March 31, 2006

By

Raja A. Jadhav, Ph.D.

Howard Meyer

April 2006

Work Performed under Contract No. DE-FC26-04NT42312

September 27, 2004 - May 31, 2006

For

U.S. Department of Energy, National Energy Technology Laboratory (NETL)

Ronald Breault, Project Manager

3610 Collins Ferry Road, P.O. Box 880

Morgantown, WV 26507-0880

Submitted by

Gas Technology Institute (GTI)

1700 S. Mount Prospect Road

Des Plaines, IL 60018

GTI Project Number 20162

Technical Point of Contact

Raja A. Jadhav, Ph.D.

Engineer, GTI

Phone: (847) 768-0807, Fax: (847) 768-0600

E-mail: raja.jadhav@gastechnology.org 


\section{DISCLAIMER}

This report was prepared as an account of work sponsored by an agency of the United States Government. Neither the United States Government nor any agency thereof, nor any of their employees, makes any warranty, expressed or implied, or assumes any legal liability or responsibility for the accuracy, completeness, or usefulness of any information, apparatus, product, or process disclosed, or represents that its use would not infringe privately owned rights. Reference herein to any specific commercial product, process, or service by trade name, trademark, manufacturer, or otherwise does not necessarily constitute or imply its endorsement, recommendation, or favoring by the United States Government or any agency thereof. The views and opinions of authors expressed herein do not necessarily state or reflect those of the United States Government or any agency thereof. 


\begin{abstract}
In this Task, several formulations of binary metal oxide-based sorbents were prepared and evaluated for capture of mercury (Hg) in simulated fuel gas (SFG) atmosphere at temperatures in the range $423-533 \mathrm{~K}$. The binary metal oxides with high surface area were found to be more effective, confirming the role of sorbent surface in mercury capture. These binary sorbents were found to be effective in capturing $\mathrm{Hg}$ at 473 and $533 \mathrm{~K}$, with $\mathrm{Hg}$ capture decreasing at higher temperature. Based on the desorption studies, physical adsorption was found to be the dominant capture mechanism with lower temperatures favoring capture of $\mathrm{Hg}$.
\end{abstract}




\section{TABLE OF CONTENTS}

ABSTRACT

LIST OF FIGURES

EXECUTIVE SUMMARY $\quad$ v

1. Experimental Methods $\quad 1$

2. Results and Discussion $\quad 1$

3. Conclusion 1 


\section{LIST OF FIGURES}

Figure 1 Mercury breakthrough plot for 5:5 wt\% Me:Me2/alumina sorbent at $473 \mathrm{~K} 2$

Figure 2 Mercury breakthrough plot for 5:5 wt\% Me:Me2/alumina sorbent at 533 K 2 


\section{EXECUTIVE SUMMARY}

Gas Technology Institute (GTI), in collaboration with Nanoscale Materials, Inc. (NanoScale), is developing and evaluating several nanocrystalline sorbents for capture of mercury from coalgasifier (such as IGCC) warm fuel gas. The focus of this study is on the understanding of fundamental mechanism of interaction between mercury and nanocrystalline sorbents over a range of fuel gas conditions. Detailed chemical and structural analysis of the sorbents will be carried out using an array of techniques, such as XPS, SEM, XRD, $\mathrm{N}_{2}$-adsorption, to understand the mechanism of interaction between the sorbent and mercury.

The proposed nanoscale oxides have significantly higher reactivities as compared to their bulk counterparts, which is a result of high surface area, pore volume, and nanocrystalline structure. These metal oxides/sulfides will be evaluated for their mercury-sorption potential in an experimental setup equipped with state-of-the-art analyzers. Initial screening tests will be carried out in $\mathrm{N}_{2}$ atmosphere, and two selected sorbents will be evaluated in simulated fuel gas containing $\mathrm{H}_{2}, \mathrm{H}_{2} \mathrm{~S}$, Hg and other gases. The focus will be on development of sorbents suitable for higher temperature (420-640 K) applications.

Activities in this Task were focused on synthesis and evaluation of several formulations of binary metal oxide-based sorbents for capture of mercury (Hg) in simulated fuel gas (SFG) atmosphere at temperatures in the range $423-533 \mathrm{~K}$. The objective of this task was to find out the synergetic effect of using two metal oxides for capture of mercury in reducing syngas.

Two different synthesis procedures were used to prepare these binary metal oxides (MeO). Surface area of the prepared sorbent was found to be sensitive to the procedure followed during the synthesis. The binary metal oxides with high surface area were found to be more effective, confirming the role of sorbent surface in mercury capture. These binary sorbents were found to be effective in capturing $\mathrm{Hg}$ at 473 and $533 \mathrm{~K}$, with $\mathrm{Hg}$ capture decreasing at higher temperature. The effect of temperature on Hg-capture suggested physical adsorption as the dominant capture mechanism with lower temperatures favoring capture of $\mathrm{Hg}$. 


\section{Experimental Methods}

Synthesis of binary sorbents

Several formulations of supported as well as unsupported mixed metal oxides were prepared. Two different synthesis procedures were used to prepare these binary metal oxides (MeO). Suitable precursor solutions of these metals were used as the source of the metals.

Evaluation of binary metal oxide sorbents for mercury capture in SFG

The binary oxide sorbents were evaluated for Hg-sorption capacity in GTI's mercury sorbent testing system. The details of the sorbent testing system and the experimental procedure are given in the 'Quarter-2 Progress Report.' Initial screening tests were carried out in $\mathrm{H}_{2}$ and $\mathrm{H}_{2} \mathrm{~S}$ containing gas stream with composition (mol \%): $\mathrm{H}_{2} / \mathrm{H}_{2} \mathrm{~S} / \mathrm{N}_{2}=25 / 0.125 /$ balance. Hydrogen was added to simulate the effect of reducing species, whereas, $\mathrm{H}_{2} \mathrm{~S}$ was added to simulated the effect of S-containing species in the gasifier fuel gas. The total flow rate of the gas was maintained at 2 slpm, whereas, the concentration of $\mathrm{Hg}$ in the gas stream was around $180 \mu \mathrm{g} / \mathrm{m}^{3}$. The sorption of mercury was carried out at temperatures 473 and $533 \mathrm{~K}$. For these tests, about $0.5 \mathrm{~g}$ of the sorbent and 225,000 hr-1 (STP) gas hourly space velocity (GHSV) was used.

\section{Results and Discussion}

\section{Evaluation of unsupported binary sorbents}

The Hg-sorption capacity of unsupported binary metals oxides was evaluated at $423 \mathrm{~K}$ in SFG. However, these sorbents did not have any capacity of $\mathrm{Hg}$ at these conditions, probably because of the low surface area of the sorbents $\left(2.2 \mathrm{~m}^{2} / \mathrm{g}\right.$ for MeO- 1 and $1.2 \mathrm{~m}^{2} / \mathrm{g}$ for MeO-2). Since Hg capture by the sorbent is essentially a surface phenomenon, a sorbent with a low surface area would give very low Hg-sorption capacity.

\section{Evaluation of supported binary metal oxides}

Since unsupported binary metal oxides did not show much affinity for Hg due to the low surface area, binary oxides based on Me and Me2 metals were supported on high surface area alumina to evaluate their effectiveness for Hg capture. Figures 1 and 2 show the breakthrough plots for 5 wt\% Me/5 wt\% Me2/alumina sorbent in $\mathrm{H}_{2} / \mathrm{H}_{2} \mathrm{~S} / \mathrm{N}_{2}$ stream at 473 and $533 \mathrm{~K}$, respectively. Comparison of Figures 1 and 2 indicates that binary metal oxide is more effective at the lower temperature of $473 \mathrm{~K}$, suggesting physical adsorption as the dominant mechanism. The Hgsorption capacity at $473 \mathrm{~K}$ during $4 \mathrm{~h}$ exposure is calculated as ca. $150 \mu \mathrm{g} / \mathrm{g}$.

\section{Conclusion}

Several formulations of supported and unsupported binary metal (Me)-based sorbents were evaluated for capture of $\mathrm{Hg}$ in $\mathrm{H}_{2} \mathrm{~S} / \mathrm{H}_{2} / \mathrm{N}_{2}$ atmosphere at temperatures 473 and $533 \mathrm{~K}$. At these conditions, supported sorbents showed moderate capacity for Hg capture. The Hg-sorption capacity at $473 \mathrm{~K}$ during $4 \mathrm{~h}$ exposure is calculated as ca. $150 \mu \mathrm{g} / \mathrm{g}$. Based on the effect of temperature on capture of $\mathrm{Hg}$ by these binary oxide sorbents, physical adsorption was found to be the dominant capture mechanism with lower temperatures favoring capture of $\mathrm{Hg}$. 


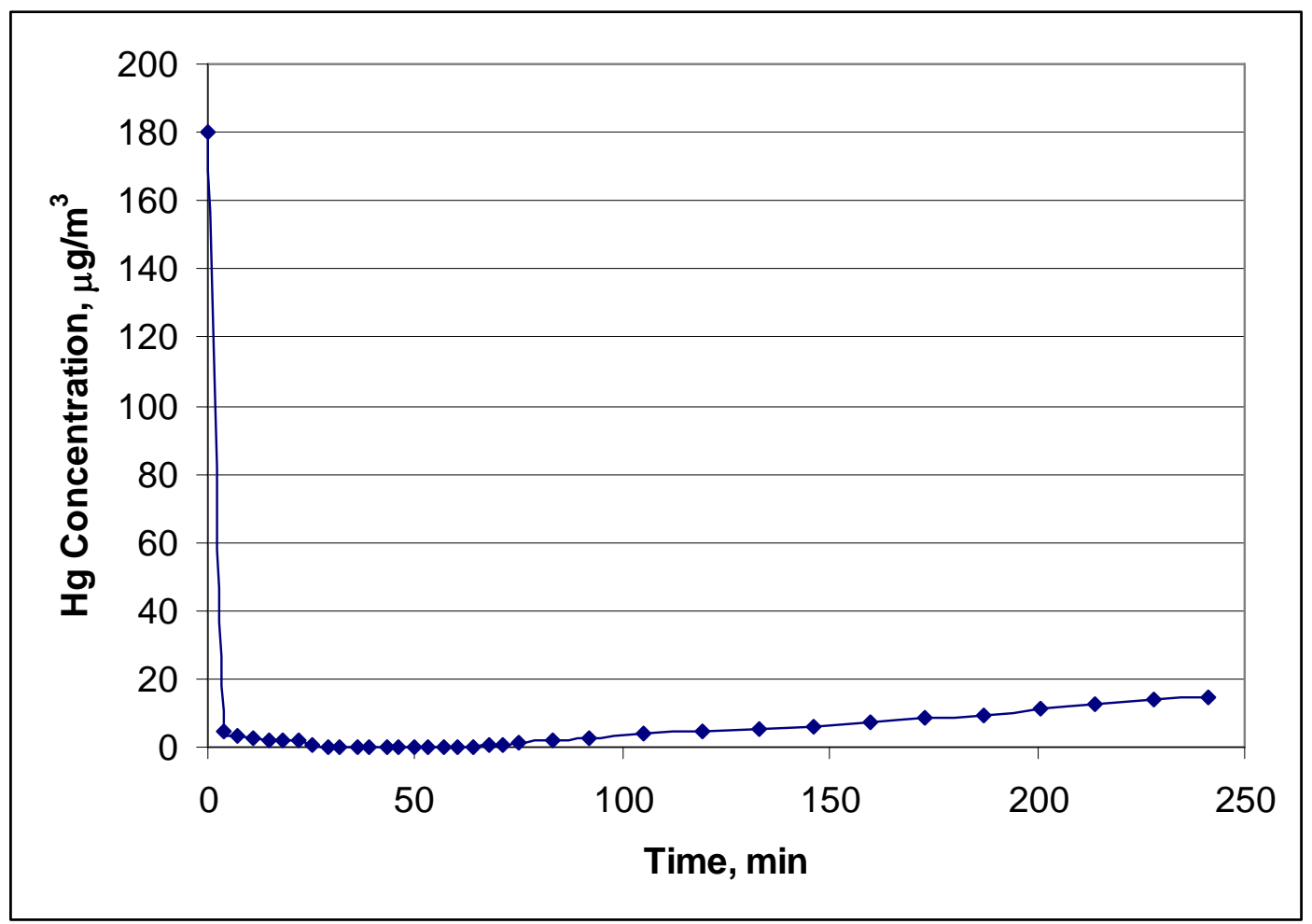

Figure 1: Mercury breakthrough plot for 5:5 wt\% Me:Me2/alumina sorbent at $473 \mathrm{~K}$

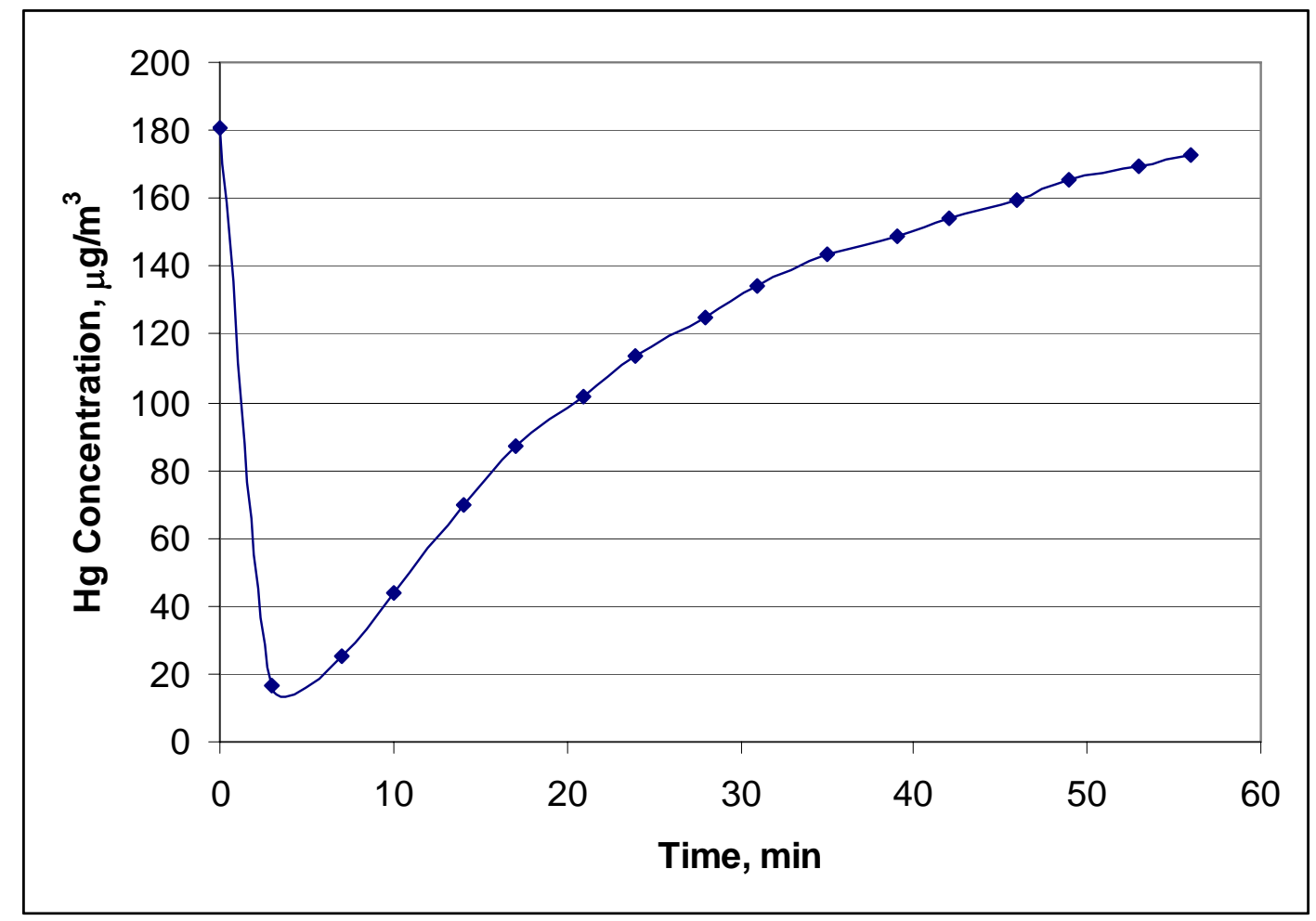

Figure 2: Mercury breakthrough plot for 5:5 wt\% Me:Me2/alumina sorbent at $533 \mathrm{~K}$ 